\title{
Airway disease in upper and lower lobes in lungs of patients with and without emphysema
}

\author{
JL WRIGHT, BARRY J WIGGS, JC HOGG \\ From the University of British Columbia Pulmonary Research Laboratory, St Paul's Hospital, Vancouver, \\ Canada
}

ABSTRACT To determine whether pathological changes in the small airways are evenly distributed throughout the lung and whether there is an association of small airway disease with emphysema, pathological abnormalities of the small airways were graded in the upper and lower lobes of 13 surgical lung specimens. Except for slightly increased degrees of respiratory bronchiolar inflammation in the lower lobe, no differences were found between the two sites, nor was there any relationship between the presence of pathological abnormalities in the small airways and the presence of centrilobular emphysema. It is concluded that the predilection of centrilobular emphysema for the upper lung zone is not associated with a difference in intensity of airway disease between upper and lower lobes.

Grading schemes for airway pathology have proved useful in the documentation of airway disease and its relation to abnormalities of pulmonary function. ${ }^{1-4}$ Surgical specimens, although theoretically ideal for studying correlations between structure and function because of preterminal changes found in cadaver lungs, often consist of a single lobe, which may not be representative of disease in the whole lung. Centrilobular emphysema, increased in patients who smoke cigarettes, is an upper lobe lesion that is based on the distribution of respiratory bronchioles. If airways disease, particularly inflammation, is directly concerned in the causation of emphysema via the production of an imbalance between proteolyic enzymes and inhibitors, it could be expected that it would be greater in the upper lobes. One study, ${ }^{5}$ using cadaver lungs, has suggested that airway inflammation tends to be greater in the lower lobes, even in the face of upper lobe emphysema, while a similar study ${ }^{6}$ found increased disease in the airways of the upper lobes.

The purpose of this study was twofold: firstly, to investigate whether airways disease is distributed preferentially in either the upper or the lower lobes; and, secondly, to identify whether, when emphysema is present, there is a shift in disease toward the affected lobe.

Address for reprint requests: Mr J L Wright, Pulmonary Research Laboratory, St Paul's Hospital, 1081 Burrard Street, Vancouver BC, Canada.

Accepted 21 November 1983

\section{Methods}

Thirteen left pneumonectomy specimens were obtained from patients undergoing resective surgery for a solitary coin lesion. All patients were male, and all were over the age of 50 .

The lungs were inflated with either $10 \%$ formalin or $2 \%$ glutaraldehyde at a standard pressure of 25 $\mathrm{cm} \mathrm{H}_{2} \mathrm{O}$, and allowed to fix for at least 24 hours. They were then sliced in a sagittal plane; the mid- ? sagittal slice was saved for the estimation of $\bar{O}$ emphysema. ${ }^{7}$ Five stratified random blocks were obtained from each of the upper and lower lobes of $\delta$ a parasagittal slice. This slice was chosen since it is known to be highly representative of disease present 을 in the whole of the lung. ${ }^{8}$ The blocks were processed in the usual fashion, embedded in paraffin, and $5 \mu$ 을 sections were cut and stained with haematoxylin and $N$ eosin, periodic acid Schiff, and Masson's trichrome.

All membranous and respiratory bronchioles in the upper and lower lobes were graded by a modification of the technique described by Cosio et al. ${ }^{\prime} \underset{Z}{\mathscr{C}}$ This requires a subjective grading of each mor- $\theta$ phological index from 0 (normal) to 3 (most abnormal). The indices were as follows: mem- $\stackrel{?}{+}$ branous bronchioles - inflammation, fibrosis, muscle hypertrophy, pigment deposition, goblet cell metaplasia, and squamous cell metaplasia; respiratory bronchioles-inflammation, intraluminal $\stackrel{\mathbb{\perp}}{\stackrel{2}{2}}$ macrophages, fibrosis, muscle hypertrophy, and pigment deposition. The number of airways graded 
Table 1 Age and smoking history of patients with differing emphysema score (means with standard deviations in parentheses)

\begin{tabular}{llll}
\hline Emphysema score & $\begin{array}{l}\text { No of } \\
\text { patients }\end{array}$ & Age (y) & $\begin{array}{l}\text { Smoking history } \\
\text { (pack y) }\end{array}$ \\
\hline 0 & 5 & $60(5)$ & $55(19)$ \\
$\begin{array}{l}2 \cdot 5-25 \\
(\text { mean }=12)\end{array}$ & 8 & $63(8)$ & $47(31)$ \\
$\geqslant \begin{array}{l}15 \\
(\text { mean }=21)\end{array}$ & 5 & $64(7)$ & $42(18)$ \\
\hline
\end{tabular}

as $0,1,2$, or 3 was calculated for each index and used to identify distribution of degree of disease. The total score for each index was obtained by adding the individual scores and expressing this as a percentage of the maximum possible score. The total pathological score was obtained by addition of the scores of all the variables.

The distribution of disease between upper and lower lobes was compared by an odds ratio analysis. ${ }^{9}$ Differences in pathological score for each variable between upper and lower lobes were tested with Wilcoxon's signed rank test, while the Wilcoxon's rank sum test was used to test for differences in the pathological variables when the patients were grouped according to their emphysema score. The five patients with an emphysema score equal to or greater than 15 were treated as a single group. To test whether there was a difference in pathology when any degree of emphysema was present, these patients were also included along with three patients who had scores greater than 0 but less than 15 to form a separate group.

\section{Results}

The age distribution and smoking histories of patients with and without emphysema were similar (table 1). There were four ex-smokers in the group with no emphysema and two ex-smokers in the group with an emphysema score equal to or greater than 15; the remainder were current smokers at the time of surgery.

\section{Disease distribution}

When the method of Thurlbeck ${ }^{7}$ is used for grading emphysema is greatest in the upper lobes until about grade 50 . The highest score in our series was 25 and therefore, on the basis of this system, the lower lobes showed only minimal degrees of destruction.

There was no difference between the upper and lower lobes for any of the pathological indices in either the membranous or the respiratory bronchioles when the data for all 13 patients were examined. Similarly, there were no differences when the cases were divided into those with no emphysema $(n=5)$ and those with any degree of emphysema $(n=8)$, or those with and without significant emphysema, designated as greater than 15 units $(n=5)$.

\section{Pathological score}

Results for membranous and respiratory bronchioles are shown in table 2 . There were no differences between upper and lower lobes for any variable when all 13 cases were considered. Compared with the upper lobes, the lower lobes of patients with an emphysema score equal to 0 had a slightly increased degree of inflammation in the

Table 2 Pathology scores for upper and lower lobes (means with standard deviations in parentheses)

\begin{tabular}{|c|c|c|c|c|c|c|c|c|}
\hline \multirow[t]{3}{*}{ Variable } & \multicolumn{2}{|l|}{ All cases } & \multicolumn{6}{|c|}{ Emphysema score } \\
\hline & \multirow[t]{2}{*}{ Upper } & \multirow[t]{2}{*}{ Lower } & \multicolumn{2}{|l|}{0} & \multicolumn{2}{|l|}{$2 \cdot 5-25$} & \multicolumn{2}{|l|}{$\geqslant 15$} \\
\hline & & & Upper & Lower & Upper & Lower & Upper & Lower \\
\hline $\begin{array}{l}\text { Total pathology score } \\
\text { Inflammation } \\
\text { Fibrosis } \\
\text { Muscle hypertrophy } \\
\text { Pigment } \\
\text { Goblet metaplasia } \\
\text { Squamous metaplasia }\end{array}$ & $\begin{array}{r}139(48) \\
39(19) \\
14(10) \\
24(18) \\
25(17) \\
23(13) \\
14(10)\end{array}$ & $\begin{array}{r}142(52) \\
37(19) \\
15(11) \\
28(20) \\
23(12) \\
27(15) \\
12(10)\end{array}$ & $\begin{array}{c}\text { MBRANO } \\
125(24) \\
33(9) \\
10(7) \\
30(17) \\
18(17) \\
21(16) \\
12(7)\end{array}$ & $\begin{array}{c}\text { S BRONCF } \\
128(48) \\
34(12) \\
9(3) \\
35(27) \\
15(10) \\
23(12) \\
12(8)\end{array}$ & $\begin{array}{l}\text { OLES } \\
148(58) \\
42(23) \\
16(11) \\
20(19) \\
29(16) \\
25(12) \\
16(12)\end{array}$ & $\begin{array}{r}151(56) \\
39(23) \\
18(13) \\
24(16) \\
28(11) \\
30(17) \\
12(12)\end{array}$ & $\begin{array}{r}165(61) \\
44(28) \\
19(12) \\
28(19) \\
33(15) \\
28(13) \\
13(12)\end{array}$ & $\begin{array}{r}173(49) \\
41(25) \\
21(17) \\
27(16) \\
32(8) \\
39(12) \\
13(12)\end{array}$ \\
\hline $\begin{array}{l}\text { Total pathology score } \\
\text { Inflammation } \\
\text { Intraluminal macrophages } \\
\text { Fibrosis } \\
\text { Muscle hypertrophy } \\
\text { Pigment }\end{array}$ & $\begin{array}{l}78(42) \\
17(12) \\
16(15) \\
10(9) \\
12(12) \\
24(15) \\
\end{array}$ & $\begin{array}{l}91(36) \\
24(10) \\
17(14) \\
12(11) \\
12(13) \\
25(19) \\
\end{array}$ & $\begin{array}{l}\text { SPIRATOI } \\
62(15) \\
13(3) \\
7(6) \\
6(4) \\
19(12) \\
16(14) \\
\end{array}$ & $\begin{array}{l}\text { BRONCl } \\
76(17) \\
23(6)^{*} \\
12(8) \\
7(3) \\
19(11) \\
14(9) \\
\end{array}$ & $\begin{array}{l}\text { PLES } \\
89(50) \\
20(16) \\
21(17) \\
12(11) \\
7(10) \\
29(15)\end{array}$ & $\begin{array}{r}101(42) \\
25(12) \\
20(16) \\
15(13) \\
8(13) \\
33(20)\end{array}$ & $\begin{array}{r}100(59) \\
22(19) \\
20(19) \\
17(12) \\
6(10) \\
34(15)\end{array}$ & $\begin{array}{r}100(59) \\
25(14) \\
19(17) \\
18(15) \\
6(10) \\
32(18)\end{array}$ \\
\hline
\end{tabular}

${ }^{*} \mathrm{p}<0.05$. 
walls of respiratory bronchioles; there was a similar though non-significant trend in the groups of patients with any emphysema or significant (score 15 or more) emphysema.

The data in table 2 display a wide standard deviation of the mean. This is indicative of the large variation of pathological scores between individual patients, who except for respiratory bronchiolitis had similar scores in the upper and lower lobes.

There were no differences in any of the pathological indices when patients with any emphysema (score 2.5-25) or significant (score $\geqslant 15$ ) emphysema were compared with patients with no emphysema. Although there was a tendency for the total pathological score to increase when emphysema was present, this was not significant.

\section{Discussion}

This study addressed the question of whether airways disease is present in a uniform or non-uniform fashion, and whether this distribution is altered when centrilobular emphysema is present. Two previous studies, which were confined to a single varible of inflammation, yielded conflicting results. ${ }^{56}$

Our data have shown that the pathological indices in membranous and respiratory bronchioles are distributed equally between upper and lower lobes. Equal pathological scores for the upper and lower lobes were found for all indices except inflammation of the respiratory bronchioles, which was increased in the lower lobes in patients with no emphysema, and tended to be increased in the lower lobes of patients with emphysema. Increases in the pathology index may represent either clusters of the more abnormal scores or a generalised increase in both minor and major degrees of abnormalities. The former, which theoretically could be produced by a localised area of severe disease, would be readily identified in the odds ratio analysis for distribution differences. We believe that a difference in airway score between the upper and lower lobes in the face of a similar distribution of scores is a more accurate finding since it suggests widespread overall increase in disease.

The study by Berend included patients with a wide range of ages and unknown smoking histories..$^{5}$ Cigarette smoking is known to be associated with inflammation of the walls of membranous and respiratory bronchioles, which contain collections of intraluminal macrophages. ${ }^{10}$ To remove any possible bias introduced by age or smoking we limited the study to left pneumonectomy specimens from men over the age of 50 who had smoked cigarettes. Six of the patients were ex-smokers, but they were included as we have previously shown that patho- logical changes in the airways do not decrease after cessation of smoking. " The total smoking history was similar in all of the study groups.

Cosio and colleagues ${ }^{6}$ identified increases in inflammation, goblet cell metaplasia, and muscle hypertrophy in membranous bronchioles, and inflammation of respiratory bronchioles in patients who smoked cigarettes. They found that the inflammatory changes were more noticeable in the upper lobes. Our data on inflammation are similar to those of Berend..$^{5}$ The apparent discrepancy between the values for respiratory bronchiolar inflammation in the two studies is explained by the different methods used. While we evaluated intramural inflammation and intraluminal macrophages as two individual variables, Berend considered them together; when our values are summed therefore they approximate to those of Berend. Our findings do, however, differ from Berend's in that we found lower lobe scores for respiratory bronchiolar inflammation to be significantly increased over upper lobe scores in those patients who were free of emphysema, while there were no differences between lobes in the scores for inflammation of the membranous bronchioles.

The proteolysis-antiproteolysis theory would suggest that inflammation of the airways is an important factor in the causation of emphysema. Leopold and Gough $^{12}$ postulated that inflammation of the $\overline{\vec{\sigma}}$ respiratory bronchioles was causally related to emphysematous lesions. If cigarette smoke incites $\rightleftharpoons$ an inflammatory reaction, it would seem reasonable that this reaction should parallel the distribution of the smoke. Anderson et al, in an experimental model, found that smoke at ambient temperatures $\stackrel{x}{x}$ preferentially went to the upper lobes. ${ }^{13}$ Particles of $\frac{0}{7}$ respirable range, at least in animals, ${ }^{14}$ are also preferentially deposited in the upper lobes. During nor- $\delta$ mal ventilation in man, however, most of the gas is distributed to the lower lobes. ${ }^{1516}$ Thus the $\frac{\text { o }}{2}$ inflammatory stimulus of gas or particles or both $\vec{D}$ may be distributed relatively evenly throughout the lungs, which might explain our results.

Cockcroft and Horne ${ }^{17}$ present the theory that the apical dominance of centrilobular emphysema is due 0 to the high ventilation-perfusion ratio in the $\tilde{\omega}$ upper lobes. They believe that $\alpha_{1}$ antiprotease is distributed according to blood perfusion, leaving theo upper lobes with a relative deficiency. Conse- $\Phi$ quently, although the inflammatory reaction in the $\stackrel{?}{+}$ apices may not necessarily be increased, the amounts of proteases are sufficient to overwhelm욤 the protective effects of the $\alpha_{1}$ antiprotease present.

In this study airway disease was not found to be $\stackrel{\square}{\stackrel{\otimes}{\alpha}}$ significantly increased when emphysema was pres- ent. Although respiratory bronchiolar inflammation 
may be slightly underestimated by an upper lobe sample, a single lobe of lung is relatively representative of disease in the whole lung, irrespective of the presence of emphysema. The predilection of centrilobular emphysema for the upper lung zones is not explained by a difference in intensity of airways disease between upper and lower lobes.

This work was supported by a grant from the Medical Research Council of Canada.

\section{References}

' Cosio M, Ghezzo H, Hogg JC, Corbin R, Loveland M, Dosman J, Macklem PT. The relations between structural changes in small airways and pulmonaryfunction tests. $N$ Engl J Med 1977;298:1277-81.

${ }^{2}$ Petty TL, Silvers W, Stanford RE. Functional correlations with mild and moderate emphysema in excised human lungs. Am Rev Respir Dis 1981;124:700-4.

${ }^{3}$ Petty TL, Silvers GW, Stanford RE, Baird MD, Mitchell RS. Small airways pathology is related to increase of closing capacity and abnormal slope of phase III in excised human lungs. Am Rev Respir Dis 1980;121:449-56.

${ }^{4}$ Berend N, Woolcock AJ, Marlin GE. Correlation between the function and structure of the lung in smokers. Am Rev Respir Dis 1979;119:695-705.

${ }^{5}$ Berend N. Lobar distribution of bronchiolar inflammation in emphysema. Am Rev Respir Dis 1981;124:218-20.

${ }^{6}$ Cosio M, Hale KA, Niewoehner DE. Morphologic and morphometric effects of prolonged cigarette smoking on the small airways. Am Rev Respir Dis 1980;122:265-71.

7 Thurlbeck WM, Dunnill MS, Hartung W. A comparison of three methods of measuring emphysema. Hum Pathol 1972;1:215-26

${ }^{8}$ Langston C, Waszkiewicz E, Thurlbeck WM. A simple method for the representative sampling of lungs of diverse size. Thorax 1979;34:527-30.

${ }^{9}$ Fleiss JL. Statistical methods for rates and proportions. 2nd ed. New York: John Wiley and Sons, 1981.

${ }^{10}$ Niewoehner DE, Kleinerman J, Rice DB. Pathologic changes in the peripheral airways of young cigarette smokers. $N$ Engl J Med 1975;291:755-8.

1 Wright JL, Lawson LM, Pare PD, Wiggs BJ, Kennedy S, Hogg JC. Morphology of peripheral airways in current smokers and ex-smokers. Am Rev Respir Dis 1983;127:474-7.

${ }^{12}$ Leopold JG, Gough J. The centrilobular form of hypertrophic emphysema and its relation to chronic bronchitis. Thorax 1957;12:219-35.

${ }^{13}$ Anderson AE, Furlaneto JA, Foraker AG. Selective venting of cigarette smoke in dichotomous ducts and preserved human bronchi. Science 1968;162:668-9.

${ }^{14}$ Brain JD, Knudson DE, Sorokin SP, Davis MA. Pulmonary distribution of particles given by intratracheal instillation or by aerosol inhalation. Environ Res 1976;11:13-33.

is Milic-Emili J, Henderson JAM, Dolovich MB, Trop D, Kaneko K. Regional distribution of inspired gas in the lung. J Appl Physiol 1966;21:749-59.

${ }^{16}$ Milic-Emili J, Henderson JAM, Kaneko K. Distribution of ventilation as investigated with radioactive gases. $J$ Nucl Bio Med 1967;11:63-8.

${ }^{17}$ Cockcroft DW, Horne SL. Localization of emphysema within the lung. Chest 1982;82:483-7. 